\title{
A study to assess the knowledge and attitude of staff nurses regarding human rights of mentally ill patients at selected hospitals of Bangalore, India
}

\section{Thapa K',Samson VW ${ }^{2}$}

${ }^{1}$ Kriti Thapa, Assistant Professor, Department of Psychiatric Nursing, B. P. Koirala Institute of Health Sciences, Dharan, Nepal; ${ }^{2}$ Vimala W. Samson, Head of Department, Department of Psychiatric Nursing, Bangalore City College of Nursing, Bangalore, India

\begin{abstract}
Background: Mental illness raises many human rights issues. People with mental disorders are exposed to a wide range of human rights violation both within and outside the health care context. People with mental illness and their families do not exercise their rights, because of lack of awareness that they have such rights, lack of knowledge about how to effectively assert their rights, and lack of confidence in asserting their rights. The most important factor in ensuring patient's rights is the knowledge, attitude and commitment of the mental health professionals.

Objectives: The objectives of the study were to assess knowledge and attitude of staff nurses regarding human rights of mentally ill patients.

Methods: A descriptive approach was adopted for the study. A total of 50 staff nurses working in psychiatric wards of general hospitals and in psychiatric hospitals of Bangalore were selected through purposive sampling technique. A structured knowledge questionnaire was used to assess level of knowledge and a four-point Likert scale was used to assess attitude of nurses regarding human rights of mentally ill patients.

Results: The overall mean knowledge score was 50 percent and the overall mean attitude score was 68.65 percent among the staff nurses.

Conclusion: The results of the study exposed the requirement of continuing education of staff nurses regarding human rights of mentally ill patients.
\end{abstract}

Key words: Attitude, Human rights, Knowledge, Mentally ill patients, Staff nurses

\section{INTRODUCTION}

T hroughout history, people with mental disabilities have suffered some of the worst indignities of any group repeatedly. Feared and misunderstood, they often have been excluded from meaningful participation in civil society and denied opportunities, taken for granted by most. Like many vulnerable groups they have endured inequality, discrimination and serious social stigma'.

Human rights encompasses the "basic rights and freedoms to which all humans are entitled." This covers a broad range of rights related to civil and political issues such as right to life and liberty, freedom of expression,

Address for correspondence

Kriti Thapa

Assistant Professor

Department of Psychiatric Nursing,

B. P. Koirala Institute of Health Sciences, Dharan, Nepal

E-mail: thapakriti04@gmail.com right to equality before the law and social, cultural and economic rights, including the right to participate in culture, the right to food and the right to education. It is critical that the rights of human beings in the event of an unsound mind or mental illness are contextualized and examined with careful consideration².

Human rights laws provide fundamental protections without qualification or exception ${ }^{3}$. People with mental disorders are particularly exposed to a wide range of human rights violation both within and outside the health care context. Violations often occur in psychiatric institutions through inadequate, degrading and harmful care and treatment as well as unhygienic and inhuman living conditions ${ }^{4}$. Issues related to consent for admission and treatment are often ignored, people are assumed to be incapable of making decisions concerning their admission and treatment because independent assessment of capacity is not undertaken ${ }^{4}$. 
The most significant and serious international effort to protect the rights of mentally ill is the United Nations General Assembly Resolution 46/119 on the Protection of Persons with Mental Illness and the Improvement of Mental Health Care, adopted in 1991 in which there are twenty five principles ${ }^{5}$. The principles focus primarily on human rights in relation to mental health system ${ }^{6}$.

Human rights issues are increasingly recognized as an area of immediate attention in the protection of persons with mental illness and in the improvement of mental health care?.

Health professionals and health authorities are most closely aware of human rights abuses and will need to play an active role in eradicating such abuses and preventing them from occurring in health institutions. This will require a clearer awareness of the rights of people with mental illness and a much more critical approach to clinical and institutional practices ${ }^{8}$.

Nurses of future cannot practice in ignorance of individual rights. Neither can the nurses ignore health care professionals and health care facilities responsibility to respect rights. The nurse's first responsibility is to be aware of the client's legal rights. The nurse's major responsibility is to follow through the client's rights with the nursing actions that ensure implementation of those rights ${ }^{9}$.

Perhaps the most important factor in ensuring patient's rights is the knowledge, attitude and commitment of the mental health professionals ${ }^{10}$.

The objectives of the study were to assess knowledge and attitude of staff nurses regarding human rights of mentally ill patients and to determine the relation between knowledge and attitude of staff nurses regarding human rights of mentally ill patients.

\section{METHODS}

A descriptive approach was adopted for the study. A total of 50 staff nurses working in psychiatric wards of general hospitals and in psychiatric hospitals of Bangalore, India were selected through purposive sampling technique. Ethical clearance was obtained from the ethical committee of the college. Formal written permission was obtained from the concerned authorities of selected hospitals of Bangalore. The written consent of the participant was obtained before data collection.

Data collection instrument used was a structured pro forma for demographic variables. A structured knowledge questionnaire was used to assess level of knowledge of nurses regarding human rights of mentally ill patients. The tool had a total of twenty items. All the items were multiple choice questions. Correct answer were given one score. A four-point Likert scale was used to assess attitude of nurses regarding human rights of mentally ill patients. It consisted of 20 statements and four columns i.e. strongly agree, agree, disagree and strongly disagree. Pilot study was conducted to assess the feasibility for the main study.

Data was collected from 9th May 2011 to 28th May 2011 and was analyzed with the help of Statistical package for Social Sciences (SPSS) version 16.

\section{RESULTS}

\section{DEMOGRAPHIC VARIABLES}

The study showed that most of the staff nurses, $26(52 \%)$ were in the age group 20-23 years (Mean \pm S.D.: $22.2 \pm$ 5.75). The result showed that the majority, 32(64\%) of the staff nurses were females. The mean income was found to be Indian Rupees $4700 \pm 68.21$. Among the total staff nurses under study, the majority, $39(78 \%)$ of them had completed General Nursing and Midwifery. The mean year of experience in psychiatry ward was $1.60 \pm 0.495$.

Table 1 shows that the overall mean knowledge score was $50 \%$ among the staff nurses. The highest mean knowledge score was found in the areas of right to treatment and seclusion and restraint (70.0\%), whereas, lowest mean knowledge score was found in the area of right to enter into legal contracts (20.0\%).

Table 2 depicts that in the area of general information, out of total respondents, $66 \%$ had the knowledge regarding role of nurse to protect rights of a psychiatric patients. Similarly, 74\% knew patient had the right to refuse treatment. Out of the total respondents, 44\% of the respondents knew the nurse's action to protect client's right to privacy. Furthermore, $70 \%$ of the respondent had the knowledge of the criteria that justify seclusion and restraint. Only $30 \%$ of the respondents knew the rights of involuntarily committed patients. Knowledge responses of the respondents in aspects of violation of patient's right ranged from $18 \%$ to $34 \%$.

The data presented in Table 3 shows that the overall mean attitude score was $68.65 \%$ among the staff nurses. The highest mean attitude score was found in the aspect of information on illness or treatment (72.33\%), whereas lowest mean attitude score was found in the aspect of forced treatment (65.87\%). 
Table 1: Knowledge of the staff nurses regarding the human rights of mentally ill patients

\begin{tabular}{|c|c|c|c|c|c|c|}
\hline & \multirow{3}{*}{ Statements } & \multirow{3}{*}{ Range score } & \multirow{2}{*}{\multicolumn{3}{|c|}{ Knowledge score }} \\
\hline & & & & & & \\
\hline S.No & Knowledge aspects & & & Mean & Standard Deviation(SD) & Mean\% \\
\hline 1 & General information & 8 & $1-7$ & 3.82 & 1.320 & 47.75 \\
\hline 2 & Right to communication & 1 & $0-1$ & 0.28 & 0.454 & 28.0 \\
\hline 3 & Right to enter into legal contracts & 1 & $0-1$ & 0.20 & 0.404 & 20.0 \\
\hline 4 & Right to privacy & 1 & $0-1$ & 0.44 & 0.501 & 44.0 \\
\hline 5 & Right to informed consent & 2 & $0-2$ & 1.08 & 0.601 & 54.0 \\
\hline 6 & Right to treatment & 1 & $0-1$ & 0.70 & 0.463 & 70.0 \\
\hline 7 & Seclusion and restraint & 1 & $0-1$ & 0.70 & 0.463 & 70.0 \\
\hline 8 & Involuntarily committed patients & 2 & $0-2$ & 0.76 & 0.771 & 38.0 \\
\hline \multirow[t]{2}{*}{9} & Violation of patient's right & 3 & $0-3$ & 0.84 & 1.017 & 28.0 \\
\hline & Combined & 20 & $2-18$ & 10.00 & 5.014 & 50.0 \\
\hline
\end{tabular}

\section{Table 2: Findings related to distribution of correct responses to the knowledge questionnaire}

\section{No. Knowledge Question}

\section{General Information}

1. Definition of human rights

2. Key international human rights instrument

3. Principal legislation of human rights in India

4. Role of nurse

5. Patient's right to refuse treatment

6. Civil rights

8. A situation presenting patient's rights

13. A situation presenting patient's rights

II. Right to communication

\section{Correct response}

$\mathbf{N}$

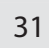

17

17

11

33

37

32

20

10

$\mathrm{n}=50$

7. Nursing action

14

$\%$

III. Right to enter into legal contracts

9. Condition to validate a contract 10

62.0

34.0

22.0

66.0

74.0

64.0

40.0

20.0

IV. Right to privacy

10. Nursing action

22

28.0

V. Right to informed consent

11. Informed consent

14. Nursing action

VI. Right to treatment

12. Criteria for adequate treatment

\section{Seclusion and restraint}

15. Criteria that justify seclusion and restraint

VIII. Involuntarily committed patient

16. Criteria for involuntary admission

17. Right of involuntarily committed patient

IX. Violation of patient's right
18. Situation
9
18.0
19. Situation
16
32.0
20. Situation
17
34.0 
Table 3: Attitude of the staff nurses regarding the human rights of mentally ill patients.

\begin{tabular}{|c|c|c|c|c|c|c|}
\hline \multirow{3}{*}{ S.No } & \multirow{3}{*}{ Attitude aspect } & \multirow{3}{*}{ Statements } & \multirow{3}{*}{ Range score } & & & $\mathrm{n}=5$ \\
\hline & & & & \multicolumn{3}{|c|}{ Attitude score } \\
\hline & & & & Mean & SD & Mean\% \\
\hline 1 & Forced treatment & 4 & $7-15$ & 10.54 & 1.908 & 65.87 \\
\hline 2 & Restrictions & 4 & $9-13$ & 11.0 & 1.178 & 68.75 \\
\hline 3 & Forced hospitalization & 3 & $6-11$ & 8.06 & 1.346 & 67.16 \\
\hline 4 & Confidentiality & 3 & $6-11$ & 8.22 & 1.055 & 68.5 \\
\hline 5 & Information on illness or treatment & 3 & $7-12$ & 8.68 & 1.168 & 72.33 \\
\hline 6 & Treatment & 2 & $3-8$ & 5.72 & 1.278 & 71.5 \\
\hline \multirow[t]{2}{*}{7} & Civil rights & 1 & $1-4$ & 2.70 & 0.931 & 67.5 \\
\hline & Combined & 20 & $47-66$ & 54.92 & 4.539 & 68.65 \\
\hline
\end{tabular}

Correlation between knowledge score and attitude score of the staff nurses regarding human rights of mentally ill.

The findings of the study revealed a positive correlation between knowledge and attitude of respondents on human rights of mentally ill patients. The correlation between knowledge and attitude indicates that staff nurses with good knowledge on human rights of mentally ill patients have a favorable attitude towards it. $(r=+0.538)$.

\section{DISCUSSION}

The overall mean knowledge score was only 50 percent among the staff nurses. This suggests that there is lack of awareness in nurses regarding rights of mentally ill. This may be due to the absence of continuing education in the health care setting they work.

The mean percentage of knowledge score on general information showed $\mathbf{4 7 . 7 5}$ percent in this study. In the area of general information, the findings of this study depicted that 66 percent knew about nurse's role to protect the rights of a psychiatric patient which is consistent with the finding of a study conducted in UK ${ }^{11}$ in which 59 percent were aware about ICN-nurse's role in safe guarding human rights. Similarly, on the aspect of general information, the study result showed that of the total respondents, 74 percent knew patient had the right to refuse the treatment which is slightly higher than the findings of a study conducted at Ain Shams University where the knowledge score of right to refuse treatment was 59.4 percent $^{12}$. Similarly, in the area of general information, only 22 percent knew about the principal legislation protecting rights of mentally ill in India whereas a study conducted in UK reported a higher percentage of 64.2 as per their knowledge regarding human rights act in $\mathrm{UK}^{13}$.
The study findings revealed a mean knowledge score of 44 percent in the area of right to privacy. A study conducted at Ain Shams University, Egypt revealed a score of 87.6 percent on this area. This finding is not in accordance with this study ${ }^{12}$. The present study documented a mean knowledge of 54 percent on right to informed consent. In contrast to the present study two studies conducted at Turkey ${ }^{14}$ and Egypt ${ }^{12}$ had a higher percentage score of 99 percent and 85.3 percent respectively on the knowledge of this right.

In the present study the area of seclusion and restraint had a mean score of 70 percent whereas a study in Hong Kong demonstrated only a modest level of knowledge of restraint use among the nurses ${ }^{15}$. The mean percentage knowledge score on rights of involuntarily committed patients is 38 percent in this study. A study conducted in England showed a slightly higher percentage of 45 percent on knowledge of patient's right at the time of an involuntary admission ${ }^{16}$.

The study finding on attitude of rights demonstrate that staff nurses favor the view that patient's right should be compromised in situations when they felt that there is a reasonable chance of benefiting the patient. This finding is supported by a study conducted in Israel to compare the patients and staff members' attitude of rights of hospitalized psychiatric patients. Their findings seem to support the often exaggerated stereotype of mental health professional as being authoritarian and not always sensitive to patient's rights which is also in accordance to this present study.

The study further expressed the view that the staff members attitudes appeared to be close to the "treatment driven model" which endorses a right to object to treatment but not a right to refuse it. The present study also supports this view of staff members ${ }^{17}$. 


\section{CONCLUSION}

The results of study exposed the requirement of continuing education of staff nurses regarding human rights of mentally ill patients. It should be made

\section{REFERENCES}

1. Gable L, Vasquez J, Gostin O, Jimenz VH. Mental health and due process in the Americas: protecting the human rights of persons involuntarily admitted to and detained in psychiatric institutions. Pan Am J Public Health. 2005;18(4/5):366-73.

2. National Human Rights Commission, Nagaraja D, Murthy $\mathrm{P}$, editors. Mental health care and human rights.Bangalore, New Delhi: National Institute of Mental Health and Neuro Sciences, India and National Human Rights Commission; 2008.

3. Gostin LO. Human rights of persons with mentally disabilities. Int J law Psychiatry. 2000;23(2):125-159.

4. Mental health:facing the challenges, building solutions: report from the WHO European ministerial conference.World Health Organization; 2005 Jan 12-15.

5. The world health report 2001- Mental health: new understanding, new hope. World Health Organization; 2001 [cited 2010 Apr 20]. Available from: http://www.who.int/whr/2001/en/whr01_ en.pdf

6. Arora T. Indian Parliament: responding to international obligations regarding the rights of mentally retarded people [Internet]. 2001 Dec [cited 2010 Apr 26]. Available from: http://www. legalserviceindia.com/articles/ip_rm.htm

7. Maingay $S$, Thornicroft, Huxley $P$, Jenkins $R$, Scmukler G. Mental health and human rights: the MI principles- turning rhetoric into action. Int Rev Psychiatry. 2002;14:19-25. mandatory that topics on rights of mentally ill patients and other legal aspects be included in the curriculum of all nursing education programmes.

8. Irmansyah I, Prasetyo YA, Minas H. Human rights of persons with mental illness in Indonesia: more than legislation is needed. Int J Ment Health Syst. 2009;3:14.

9. Verolyn Rae Bolander. Basic nursing, a psycho physiologic approach. $3^{\text {rd }}$ ed. Philadelphia (Pennsylvania): W.B Saunders; 1994.

10. Stuart GW, Laraia MT. Principles and practice of psychiatric nursing. $8^{\text {th }}$ ed. New Delhi: Elsevier; 2005.

11. Chamberlain M. Human rights education for nursing students. Nurs Ethics. 2001 May;8(3):211-22.

12. Shazly M, Fakhry S, Mohamed R. Nurses interns versus patients perception regarding Patient Rights. Egyptian Journal of Health Care. 2010;1(1):65-75.

13. Passmore K, Leung WC. Psychiatrists' knowledge of human rights act and its relevance to mental health practice: a questionnaire survey. Med Sci law. 2003;43(2):136-140.

14. Ozdemir MH, Can IO, Ergonene TA, Hilal A, Onder $M$, Meral D. Midwives and nurses awareness of patients' rights. Midwifery. 2009;25:756-65.

15. Soliday SM. A comparison of patient and staff attitudes toward seclusion. J Nerv Ment Dis. 1985 May;173(5):282-91.

16. Tancredi L, Clark D. Psychiatry and legal rights of patients. Am J Psychiatry [Internet]. 1972 Sept [cited 2010 May 3];129(3):328-30. Available from: http:// hinari-gw.who.int/whalecomajp.psychiatryonline. org/whalecom0/cgi/reprint/129/3/328

17. Roe D, Weishnut DJ, Jaglom M, Rabinowitz J. Patients' and staff members' attitudes about the rights of hospitalized patients. Psychiatr Serv. 2002 Jan;53(1):87-91. 